\title{
Utilization of Vacuum-Formed Plastic Membranes for the Production of Lightened HPC Panels
}

\author{
Jakub ŘEPKA $A^{1,2, a^{*}}$, Tomáš VLACH ${ }^{1,2, b}$, Lenka LAIBLOVÁ ${ }^{1,2, c}$, \\ Zuzana JIRKALOVÁ ${ }^{2, \mathrm{~d}}$ and Petr HÁJEK ${ }^{1, \mathrm{e}}$ \\ ${ }^{1}$ Building Structures, Faculty of Civil Engineering, CTU in Prague, 16629 Prague, CZ \\ 2University Center for Energy Efficient Buildings of CTU in Prague, 27343 Buštěhrad, CZ \\ arepka.jakub@cvut.cz, btomas.vlach@cvut.cz, lenka.laiblova@cvut.cz, \\ dzuzana.jirkalova@cvut.cz, epetr.hajek@cvut.cz
}

\begin{abstract}
Keywords: Plastic Membrane, Vacuum-formed, High-performance Concrete, Textile Reinforcement.
\end{abstract}

\begin{abstract}
This paper describes the utilization of vacuum-formed plastic membranes for the production of lightened panels made of high-performance concrete with technical textile reinforcement. The use of vacuum-formed plastic membranes is aimed to reduce the cost and increase the efficiency of production of concrete elements with highly profiled surface. Studded plastic membrane is cheap alternative to silicone or steel and while it provides slightly lower precision of manufacturing it surpasses especially the steel alternative in the terms of demoulding, since it has not sharp edges and can be easily bended.

Second part of the article focuses on the limitations given by the lightening and the approach to reduce them while maintaining the reduction of material usage. The cross-section weakened by lightening in comparison to the un-lightened specimens leads to earlier development of cracks in concrete matrix and lower ultimate bending strength caused by shear failure of the lightened crosssection. The development of cracks in concrete matrix cannot be easily controlled while maintaining the same level of lightening but by addition of another layer of the reinforcement it is possible to achieve similar ultimate bending strength as in the case of elements with full crosssection and same thickness.
\end{abstract}

\section{Introduction}

There are higher requirements for the forming technique in the case of concrete elements with a highly profiled surface. These are in particular the requirements made by more complicated demoulding. There is a risk of damaging immature highly profiled concrete elements as well as the mould which should provide the longest possible service life. Both silicone and steel mould-inserts used to achieve the demanded profiling provide high quality but at very high prices. For thin elements in which there is no risk of deformation of a more flexible mould-insert by small volume of the concrete, it would be possible to use thin profiled foil insert placed in a mould with a smooth surface. Due to the easy manufacturing process and the high variability of the profiling, it would be possible to effectively utilize vacuum-formed plastic membranes. Vacuum-formed plastic membranes lack the service life of steel moulds, but they can be produced in large quantities at a fraction of the cost. And since the studded plastic membrane can be easily bent, demoulding of the concrete elements would be much easier than in the case of the steel.

Majority approach to the research of lightened panels made of textile reinforced concrete is narrowly focused on sandwich structures, where the concrete is used only for the face sheets and the core is made of other rigid but light-weight material [1-4]. Previous research focused on a different approach, specifically one-sided lightening of thin concrete panels [5-7]. This design proved to be quite efficient in the terms of mechanical performance but it was the matter of production which turned out to be quite problematic. Even for specimens with smaller dimensions it was difficult to remove the silicone mould-insert without damaging it or the immature concrete. This article aims to prove that those complications can be solved by the utilization of the studded plastic membranes. 


\section{Materials}

Studded plastic membrane. To determine whether the studded plastic membrane would be suitable alternative to silicone and steel mould inserts, it was decided to use commercially available product which would provide the most similar lightening to the design used in previous experiments [5-7]. The specific studded membrane used for this experiment is LITHOPLAST $^{\circledR}$ SANA, polyethylene membrane with square studs and thickness of $0.8 \mathrm{~mm}$. For specimens with thickness of $18 \mathrm{~mm}$ it provided lightening equal to $20 \%$ of their volume.

Textile reinforcement. Due to the specific dimensions of the used studded membrane, it was necessary to prepare the textile reinforcement manually (Fig. 1a). The grid of technical textile was woven from carbon roving Tenax ${ }^{\circledR}$-E HTS40 F13 24K with 1600 tex. Epoxy resin Sikafloor ${ }^{\circledR}-156$ was used as a binder and to increase the tensile strength of the roving [8,9]. Silica sand applied before hardening of the epoxy resin was used to increase the cohesion between the concrete matrix and the reinforcement $[10,11]$. The reinforcement supports maintaining constant distance between reinforcement grids were 3D printed (Fig. 1b). It was designed to accommodate two or three layers of reinforcement, depending on the current setting (Fig. 1c).
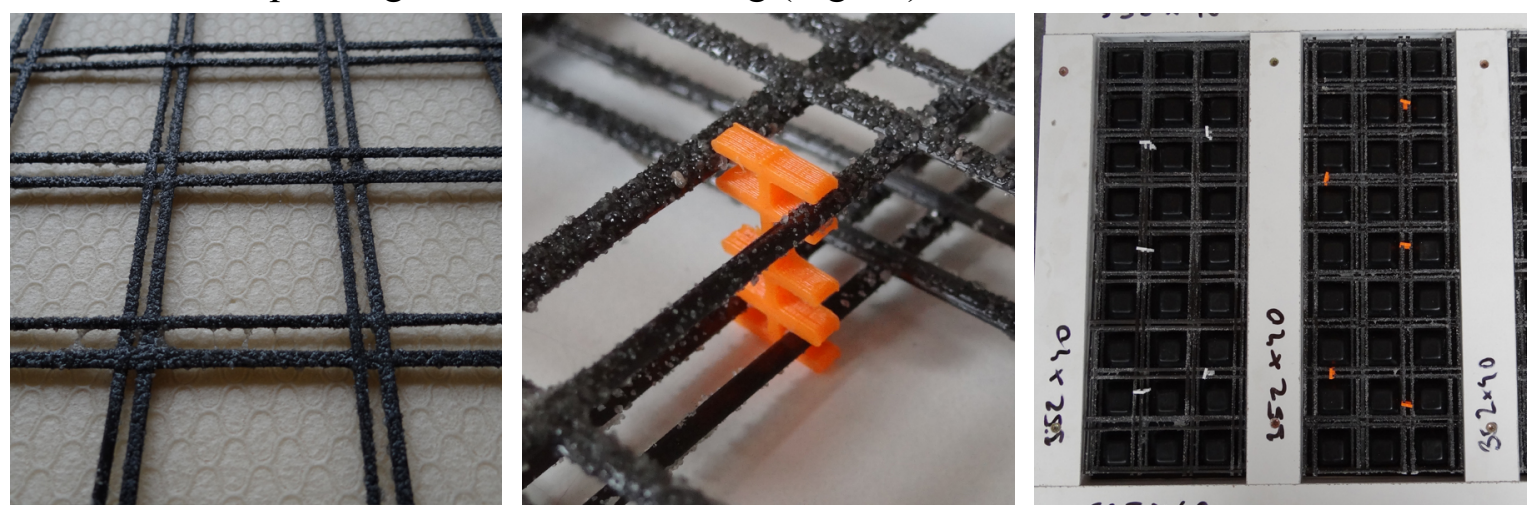

Fig. 1: Woven textile reinforcement (a); 3D printed support (b); reinforcement in mould (c)

Concrete. The high-performance concrete used in this experiment was developed at the Department of Building Structures, Faculty of Civil Engineering, Czech Technical University in Prague. Compressive strength tested on cubes with sides of $100 \mathrm{~mm}$ was equal to $140.5 \mathrm{MPa}$ according to the standard EN 12390-3. Tensile strength while bending tested on beams with dimensions of $160 \times 40 \times 40 \mathrm{~mm}$ was equal to $15.4 \mathrm{MPa}$ according to standard EN 12390-5. Water-cement ratio of the mixture is 0.25 and the largest used aggregate has the diameter of $1.2 \mathrm{~mm}$.

\section{Technology}

The use of the studded plastic membrane provides one major advantage which is the very easy demoulding. The first reason for that is that the concrete matrix does not stick to the plastic membrane even without the separator application. The second reason is that the vacuum-formed plastic membrane does not have any sharp edges which could prove difficult to demould. The last and the most important reason is that the studded membrane can be easily deformed and bended therefore it can be slowly pealed of the immature concrete without the risk of damaging it. The profiled surface of lightened specimens (Fig. 2a) was very smooth and almost seamless (Fig. 2b) as a result of the utilization of the studded membrane.

Based on the previous research there were two approaches to the placement of the studded membrane into the mould. The first one was to place the studded membrane on the bottom of the un-profiled mould before casting of the concrete. This approach was easier to execute but the quality of the flat un-profiled surface and edges around it was insufficient. The second approach was to push the studded membrane supported against bending into the immature concrete and push out the excessive air from it. It was harder to align the position of the studs and the reinforcement but as a result the quality of both surfaces was very high. 

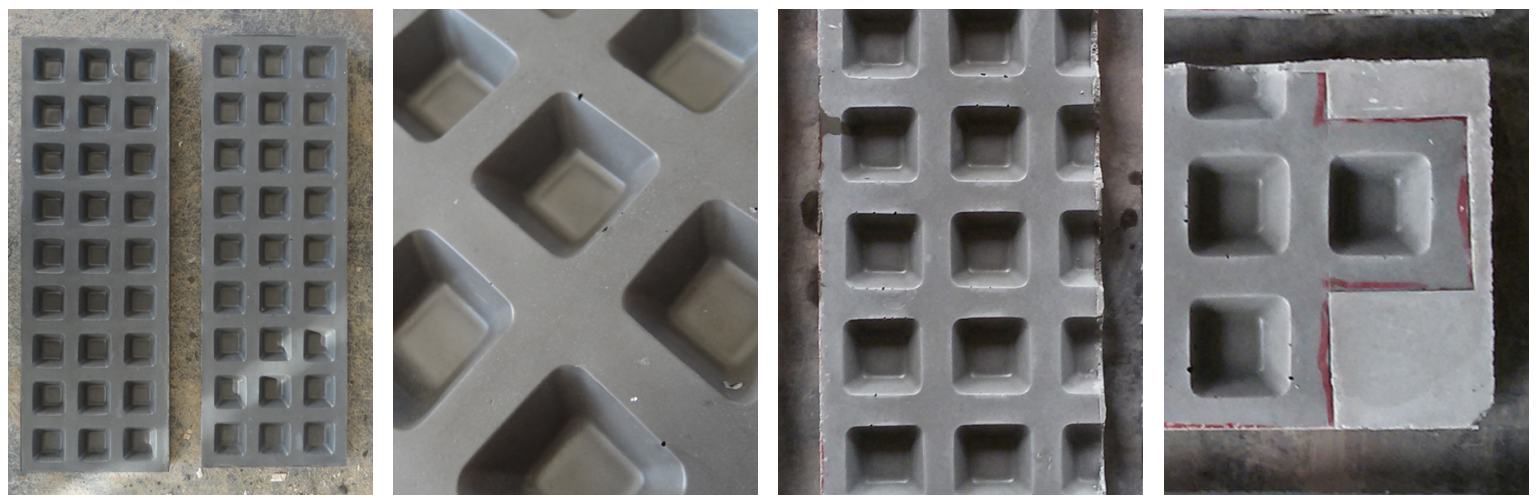

Fig. 2: Lightened specimens (a); surface detail (b); formatting of the plastic membrane (c;d)

The use of vacuum-formed plastic membrane allows high degree of variability and the possibility of easy adaptation to the moulding requirements of the manufactured elements. Vacuumformed plastic membrane can be easily cut into smaller parts, not only between the studs, but the cuts can also be directed across the studs (Fig. 2c;d). Cutouts in the studded membrane can be utilized to strengthen the anchoring points. Leaving the space between the two parts of studded membrane can create reinforcing frame. By combination of studded membranes with different concentration of studs and their dimensions it would be possible to efficiently adapt the lightening to the anticipated load distribution.

\section{Four-Point Bending Test}

Previously tested lightened specimens proved to be efficient when subjected to the four-point bending test in comparison to specimens of equal volume and therefore smaller thickness, but achieved considerably lower ultimate bending strength in comparison to specimens of the same thickness and full-cross section [5,6]. Similar results (Fig. 3) were obtained with the use of studded plastic membrane for lightening of the specimen with two layers of reinforcement (Fig. 4). The crack development started at approximately half the load compared to un-lightened specimens and the ultimate bending strength was lower by $21.5 \%$ on average. Lightened specimens also had slightly lower rigidity as the increment of displacement with increasing load was higher.

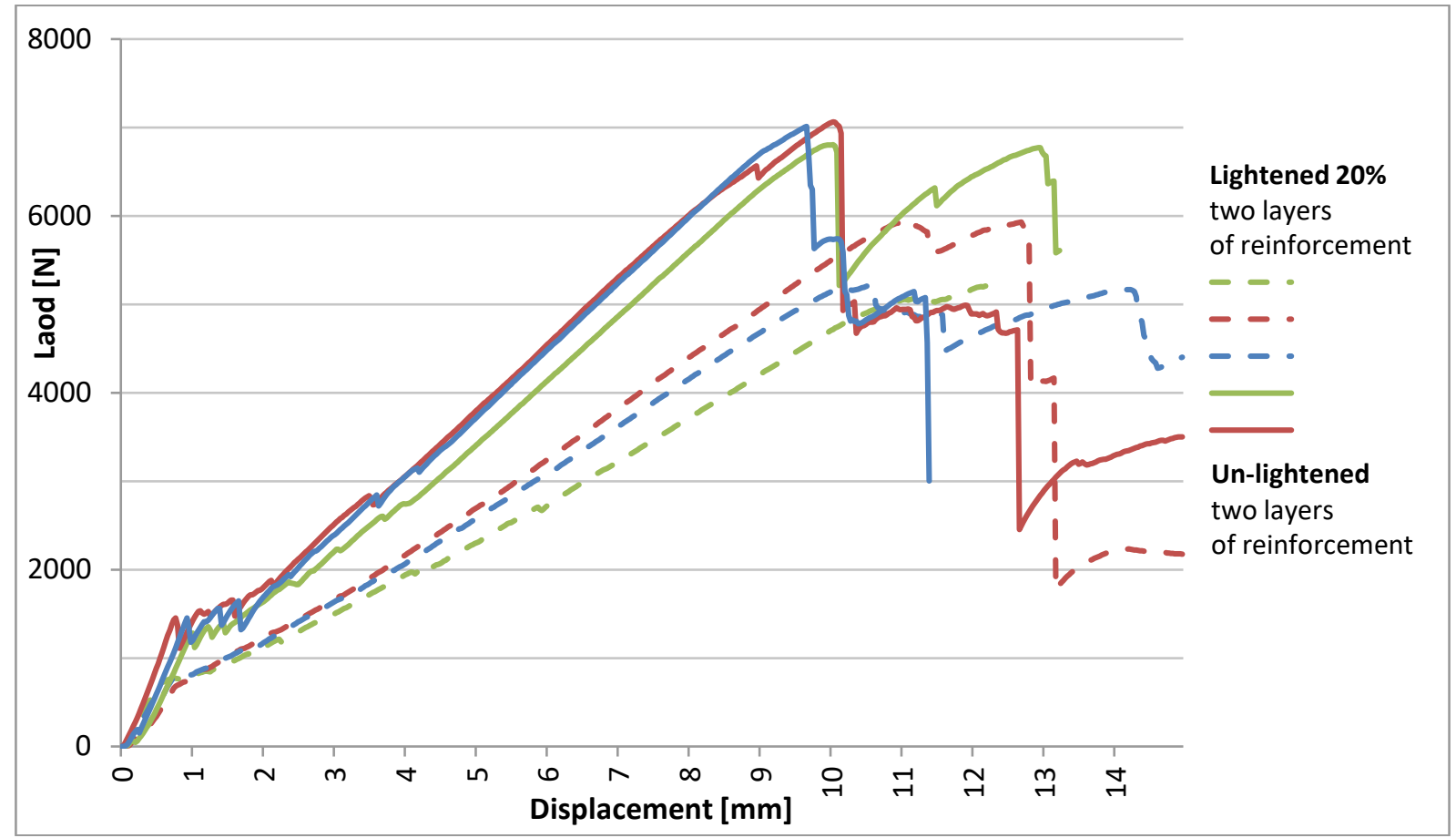

Fig. 3: Un-lightened specimens $x$ lightened specimens with 2 layers of textile reinforcement 


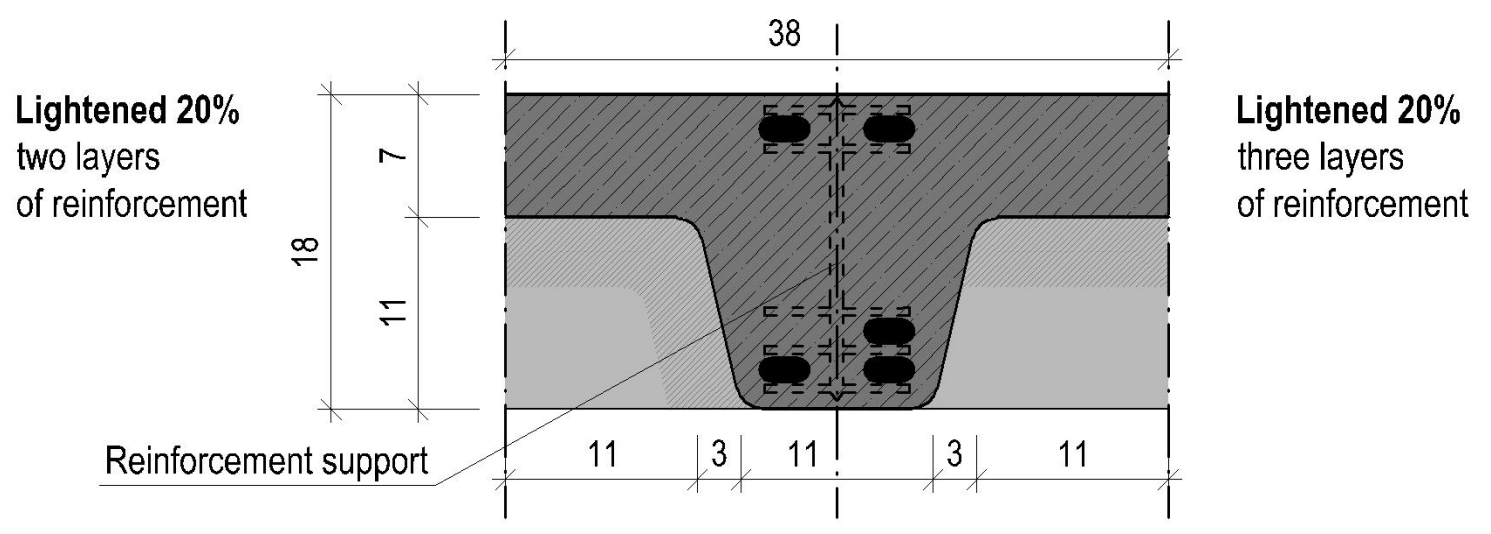

Fig. 4: Cross-section of lightened specimens with two/three layers of reinforcement

The main cause of the lower ultimate bending strength of the lightened specimens proved to be the shear failure of the weakened cross-section. Therefore another set of specimens with the similar lightening of $20 \%$ and one additional layer of reinforcement (Fig. 4) was created to establish whether there is a simple solution to overcome this limitation and achieve similar results as in the case of un-lightened specimens.

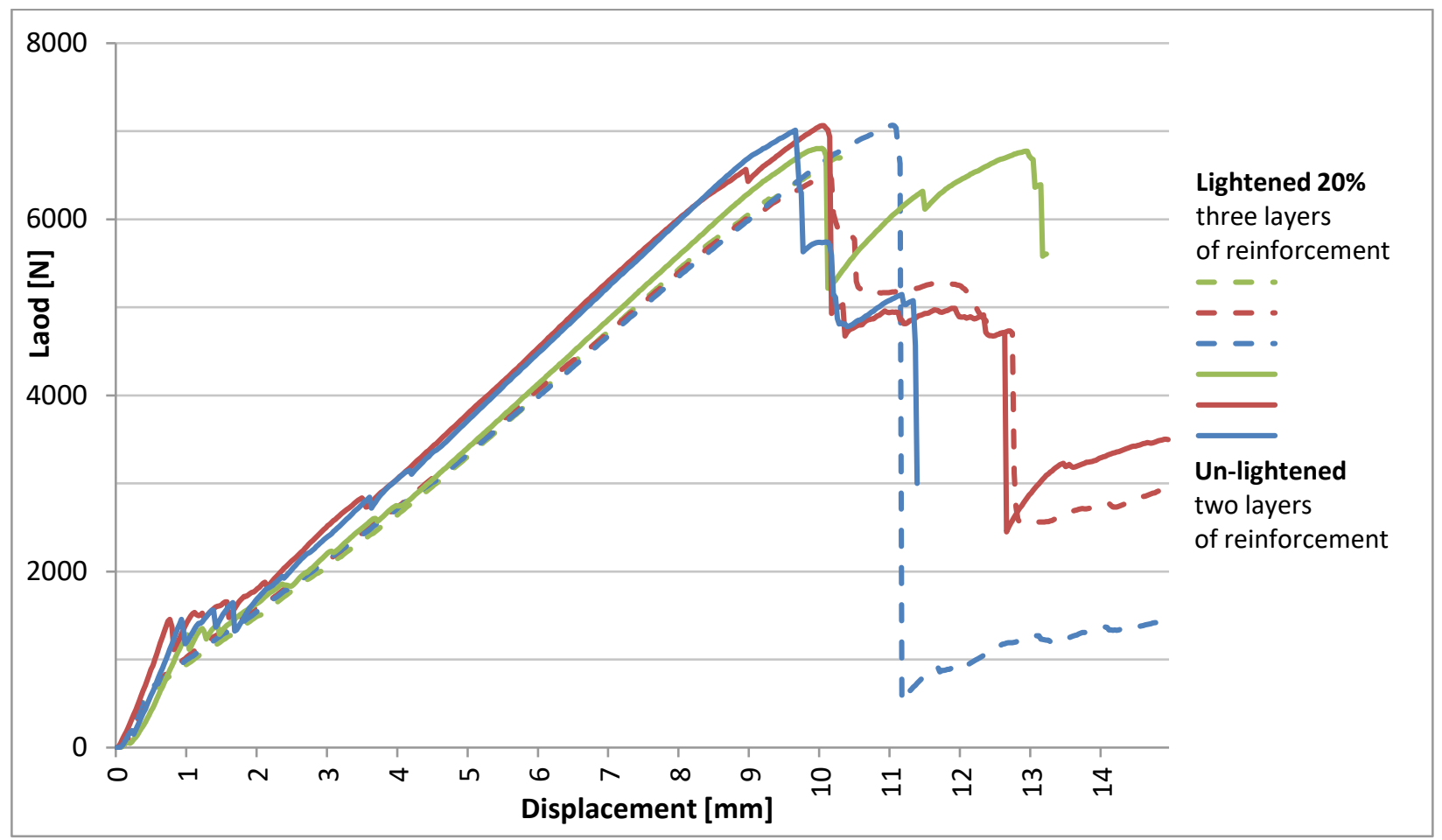

Fig. 5: Un-lightened specimens $x$ lightened specimens with 3 layers of textile reinforcement

The development of the first crack was due to the later activation of the textile reinforcement similar to the lightened specimens with two layers of the reinforcement but the ultimate bending strength considerably improved (Fig. 5) despite that the collapse was still caused by shear failure. The deflection at the same load as for the un-lightened specimens is slightly greater but the difference in the ultimate bending strength compared to the specimens with full cross-section was only $2.6 \%$ on average. The rigidity was also almost identical.

\section{Conclusions}

The utilization of vacuum-formed plastic membranes for the production of lightened panels made of high-performance concrete proved to be very efficient. Studded plastic membranes are very easily adjustable to the demanded dimensions and can be fitted in any kind of mould. The process of demoulding was significantly simplified in the comparison to the previous experiments, which used 
mould-inserts made of silicone. The studded membrane was easily deformed and pealed out of the concrete element. The use of the plastic membrane also contributed to high quality of the concrete surface.

Second part of the article confirmed that the lower ultimate bending strength of the lightened concrete panels caused by shear failure can be improved to the level of the un-lightened panels by increasing the tensile strength of the textile reinforcement. It should however be subjected to the LCA analysis, to establish whether or not the addition of another layer of reinforcement can be justified by the reduction of used concrete. But due to the related advantage of easier transportation and manipulation on site, lightened panels with more reinforcement should prove to be the better alternative in thorough LCA analysis.

Besides the LCA analysis, further research will focus on the lightening of concrete elements using lab prepared vacuum-formed plastic membrane allowing lightening of elements to a greater extent than it is currently possible with the commercially available studded membranes.

\section{Acknowledgements}

This work was supported by the TA CR 11124311 3111702A124 - Subtle Concrete Furniture and Small Structures for the Railways Stations and by the Ministry of Education, Youth and Sports within National Programme I, project No. LO1605. Further support was also given by Student Grant Competition, SGS18/110/OHK1/2T/11 - Thin Large Format Panels Made of TRC with Profiled Cross-Section for Environmentally Efficient Facade Design. The studded plastic membrane was provided by the company LITHOPLAST s.r.o. The authors would like to acknowledge with gratitude all the financial help that was provided in order to support this original research.

\section{References}

[1] M. Mastali, I.B. Valente, Joaquim A.O. Barros, Delfina M.F. Gonçalves, Development of Innovative Hybrid Sandwich Panel Slabs: Experimental Results, Composite Structures, 133 (2015) 476-498.

[2] A. Junes, A. Si Larbi, An Indirect Non-Linear Approach for the Analysis of Sandwich Panels with TRC Facings, Construction and Building Materials, 112 (2016) 406-415.

[3] L. Wang, W. Liu, H. Fang, L. Wan, Behavior of Sandwich Wall Panels with GFRP Face Sheets and a Foam-GFRP Web Core Loaded Under Four-Point Bending, Journal of Composite Materials, 49 (2015), 2765-2778.

[4] A. Chira, A. Kumar, T. Vlach, L. Laiblová, P. Hájek, Textile-Reinforced Concrete Facade Panels with Rigid Foam Core Prisms, Journal of Sandwich Structures and Materials, 18 (2016), 200-214, ISBN 1530-7972.

[5] T. Vlach, P. Hájek, C. Fiala, L. Laiblová, J. Řepka, P. Kokeš, Waffle Facade Elements from Textile Reinforced High Performance Concrete, Proceedings of HiPerMat 2016 - 4th International Symposium on Ultra-High Performance Concrete and High Performance Construction Materials (2016).

[6] J. Řepka, T. Vlach, L. Laiblová, P. Hájek, M. Ženíšek, P. Kopecký, Thin Lightweight Panels Made of Textile Reinforced Concrete, Solid State Phenomena, 259 (2017), 238-243, ISSN 1662-9779.

[7] L. Laiblová, T. Vlach, J. Řepka, M. Ženíšek, P. Hájek. Lightweight TRC Facade Panels with the LEDs, Key Engineering Materials, 760 (2018), 151-146, ISBN 978-3-0357-1240-7.

[8] J. Hegger, S. Voss, Investigations on the Bearing Behaviour and Application Potential of Textile Reinforced Concrete, Engineering Structures, (2008) 2050-2056. 
[9] W. Graf, A. Hoffman, B. M'oller, J.-U. Sickert, F. Steinigen, Analysis of Textile-Reinforced Concrete Structures Under Consideration of Non-Traditional Uncertainty Models, Engineering Structures, 29 (2007) 3420-3431.

[10]Q. Li, S. Xu, Experimental Research on Mechanical Performance of Hybrid Fiber Reinforced Cementitious Composites with Polyvinyl Alcohol Short Fiber and Carbon Textile, Journal of Composite Materials, 45 (2011), 5-28.

[11]S. P. Yin, M. W. Na, Y. L. Yu, J. Wu. Research of the Flexural Performance of RC Beams Strengthened with TRC under the Coupling Action of Load and Marine Environment, Construction and Building Materials, 132 (2017), 251-261. 